\title{
Out-Door Air Pollution Levels in Vehicular-Traffic Junctions in Nsukka Metropolis, Enugu Metropolis and Awgu Semi-Urban Area in Enugu State, Nigeria
}

\author{
Okeke Onyeka' ${ }^{1}$, Okeke Cecilia Ifeyinwa ${ }^{2}$, Ezeh Ernest ${ }^{3}$, Ikusika Bamidele Adunola ${ }^{4}$, \\ Nwigwe Juliet Onyinye ${ }^{4}$ \\ ${ }^{1}$ Plastic Production Unit, Scientific Equipment Development Institute, Akwuke, Enugu State, Nigeria \\ ${ }^{2}$ National Engineering Design and Development Institute, Nnewi, Anambra State, Nigeria \\ ${ }^{3}$ Department of Chemical Engineering, Nnamdi Azikiwe University, Awka, Anambra State, Nigeria \\ ${ }^{4}$ Department of Pure and Applied Sciences, Federal College of Dental Technology and Therapy, Enugu, Enugu State, Nigeria \\ Email: onyekaokeke207@yahoo.com
}

How to cite this paper: Onyeka, O.O., Ifeyinwa, O.C., Ernest, E., Adunola, I.B. and Onyinye, N.J. (2020) Out-Door Air Pollution Levels in Vehicular-Traffic Junctions in Nsukka Metropolis, Enugu Metropolis and Awgu Semi-Urban Area in Enugu State, Nigeria. Open Journal of Air Pollution, 9, 105-115.

https://doi.org/10.4236/ojap.2020.94007

Received: November 7, 2020

Accepted: December 11, 2020

Published: December 14, 2020

Copyright $\odot 2020$ by author(s) and Scientific Research Publishing Inc. This work is licensed under the Creative Commons Attribution International License (CC BY 4.0).

http://creativecommons.org/licenses/by/4.0/

\begin{abstract}
Studies were carried out to investigate the outdoor air pollution levels in vehicular traffic junctions in the major cities of Nsukka, Enugu and semi-urban area of Awgu all in Enugu State, Nigeria using standard analytical procedures. $\mathrm{PM}_{2.5}$ was collected using Envirotech air sampler, APM 550 and analyzed gravimetrically. Other determined air pollutant gases such as $\mathrm{SO}_{2}, \mathrm{NO}_{2}, \mathrm{O}_{3}$ and $\mathrm{CO}$ were analyzed using colorimetric techniques. The mean hourly traffic density in the vehicular traffic junctions in Nsukka metropolis, Enugu metropolis and Awgu were 2015, 2873 and 587 respectively. The mean range of values of $\mathrm{PM}_{2.5}, \mathrm{NO}_{2}, \mathrm{SO}_{2}, \mathrm{O}_{3}$ and $\mathrm{CO}$ in vehicular traffic junctions within the investigated environments were $1.67-12.16 \mu \mathrm{g} / \mathrm{m}^{3}, 3.72-23.83 \mu \mathrm{g} / \mathrm{m}^{3}, 2.96$ $30.09 \mu \mathrm{g} / \mathrm{m}^{3}, 5.45-66.54 \mu \mathrm{g} / \mathrm{m}^{3}$ and $1.18-15.17 \mathrm{ppm}$ respectively. The mean levels of the determined air pollutants in the air around vehicular traffic junctions in Nsukka metropolis, Enugu metropolis and Awgu semi-urban area differed significantly. The mean levels of $\mathrm{PM}_{2.5}$, and $\mathrm{CO}$ in the air around vehicular traffic junctions in Enugu metropolis and $\mathrm{CO}$ in the air around traffic junctions in Nsukka metropolis were above the recommended permissible limits. Traffic density was therefore seen as the single most important factor contributing to the varying air pollution levels observed in the investigated environments.
\end{abstract}

\section{Keywords}

Air Pollution, Vehicular Traffic Junctions, $\mathrm{PM}_{2.5}$, Carbon II Oxide, Sulphur IV Oxide, Nitrogen IV Oxide and Ozone 


\section{Introduction}

Traffic related sources of air pollution are drawing increasing concerns from interested exposure assessors, epidemiologists, as well as toxicologists [1]. Air pollution and its public health impacts are drawing increasing concern from the environmental health research community, environmental regulatory agencies, industries, as well as the public.

Outdoor air pollution is a major environmental health problem affecting everyone in low, middle and high income countries of the world [2].

People living in low and middle income countries disproportionately experience the burden of outdoor air pollution with the greatest burden in South-East, Asia and Africa [3].

Air pollution is the introduction of chemicals, particulate matter or biological materials into the air that cause harm and discomfort to humans and other living organisms within such an environment [4].

The association of air pollution with human health is widely known as there are many health risks associated with air polluted environment.

According to [5], in many urban environments, there has been a continuous deterioration of ambient air and human health with the increase in population, industrialization, and urbanization.

[6], stated that the emissions of toxic pollutants such as particulate matter $\left(\mathrm{PM}_{2.5}\right.$ and $\left.\mathrm{PM}_{10}\right)$ and gases like ozone, sulphur IV oxide, carbon monoxide and nitrogen oxides $\left(\mathrm{NO}_{\mathrm{x}}\right)$ through anthropogenic activities have significantly aggravated health challenges related to air pollution.

Air pollution in urban centers' has increased rapidly due to high population density, increased number of motor vehicles, use of fuels with poor environmental performance, poorly maintained transportation systems and above all ineffective environmental regulations and policies [7].

Studies have indicated that vehicles are the major source of air pollution in most cities across the world [8]. [9] stated that the major reasons for the high level of vehicular emission are the large number of vehicles on congested streets, poor quality vehicles, poor quality fuels usage, maintenance systems and ineffective transport management and the use of two-smoke engine vehicles on the road.

The most common air-pollutants associated with vehicular emission in the urban environment include, sulphur IV oxide $\left(\mathrm{SO}_{2}\right)$, nitrogen IV dioxide $\left(\mathrm{NO}_{2}\right)$ and nitrogen II oxide (NO), carbon monoxide, (CO), volatile organic compounds (VOCs), ozone $\left(\mathrm{O}_{3}\right)$, suspended particulate matter (SPM) and lead $(\mathrm{Pb})$ [10].

According to [11], air pollution is believed to kill more people worldwide than AIDS, malaria, breast cancer or tuberculosis.

Research has shown that children and elderly are particularly vulnerable to the health impacts of air pollutants such as $\mathrm{O}_{3}$, particulate matter and other air-borne pollutants while exposure to high concentrations of $\mathrm{NO}_{2}, \mathrm{SO}_{2}$, and $\mathrm{CO}$ is associated with adverse health impacts [9]. All the particulate matters of varying siz- 
es in combination with other air pollutants (gases, aromatic hydrocarbons and metals etc.) have been found associated with health problems including aggravated asthma long cancer, chronic obstructive pulmonary disease (COPD), cardiovascular diseases and premature death [12].

Deteriorating air quality and air pollution has been found to be associated with chronic morbidity, mortality and impacts on birth outcomes especially traffic related pollution releasing noxious gases into the atmosphere [5]. The elderly, the young and those with cardio-pulmonary disease, or severe bronchitis, are the most vulnerable to air pollution exposure with children at a greater risk. Air pollution can cause coughing, burning eyes and breathing problems while in the long run may even contribute to life-threatening diseases such as cancer [5].

A 2013 assessment by international agency for research on cancer concluded that outdoor air pollution is carcinogenic to humans with the particulate matter component of air pollution most closely associated with increased cancer incidence, especially lung cancer [13].

Ambient (outdoor) air pollution in both cities and rural areas was estimated to cause 4.2 million premature deaths worldwide in 2016 [14]. Nsukka and Enugu are two major metropolitan cities in Enugu State, Nigeria, with high flow of vehicular activities as a result of increased economic activities and government offices owing to the peaceful nature of the state while Awgu is a semi-urban area located on the outskirts of Enugu capital.

Increased vehicular activities have been observed in these three environments (Nsukka, Awgu and Enugu) in recent times due primarily to urbanization, job transfer, occupational change, life style and economic exigency. Despite the installation of traffic light at strategic junctions in the studied environments, motorists often violate the traffic light rule leading to long periods of gridlock and snarls especially during morning and evening period on each day.

Although the state government has floated an agency to manage the road use and traffic control in these environments, the violations of road use and traffic control by motorists are common occurrence, coupled with the fact that vehicles at different physical conditions and age still ply the roads unchecked.

Vehicular emission during rush hours in the morning period when school, civil service and other economic activities are commencing and in the evening period at close of economic activities often results in long hours of traffic snarl, a common site in the three studied environments. With the rise in respiratory related illnesses in major cities in developing economics such as Nigeria, studies was therefore carried out to assess the outdoor air pollution levels in vehicular traffic junctions in Nsukka, Enugu and Awgu environments in Enugu State, Nigeria.

\section{Materials and Methods}

The sampling locations for each of the three studied environments (Nsukka, Awgu and Enugu) were purposely selected based on location features such as 
intersections, nearness to market or school and proximity to human and economic activity. Awgu served as the control environment in this study. Analysis of the ambient air pollutants, were carried out as approved by [15] for specific parameters. The relative humidity was measured using a logger fitted with relative humidity probe (Testo 450 ) hydrogrometer. $\mathrm{PM}_{2.5}$ was measured using Envirotech air sampler APM550. The APM 550 Envirotech air sample is a micro processor-controlled low volume sampler which measures logs flow rates and meteorological parameters. Ambient air passes through a $\mathrm{PM}_{2.5}$ sampling head were particles were collected and analyzed gravimetrically. The mass of particulate matter $\left(\mathrm{PM}_{2.5}\right)$ was calculated and expressed in microgram per cubic meter of air $\left(\mu \mathrm{g} / \mathrm{m}^{3}\right)$.

The sampling of $\mathrm{SO}_{2}, \mathrm{NO}_{2}, \mathrm{O}_{3}$ and $\mathrm{CO}$ from air was carried out using the absorption train technique as described by [9]. The technique involves the absorption of pollutant gas from air into a reagent solution. Sampling was conducted twice a day (once in the morning, 8-11 am and once in the evening, 5-7 pm) for six weeks.

The absorption train consists of various components which include, a set of flow rate calibrated orifices and impingers containing absorbing solutions for $\mathrm{SO}_{2}, \mathrm{NO}_{2}, \mathrm{O}_{3}$ and $\mathrm{CO}$ separately. The absorbing solutions were sodium tetrachloromercurate for $\mathrm{SO}_{2}$, a mixture of $\mathrm{N}$-(1-napthyl)-ethylene diamine dihydrochloride and sulphamic acid in glacial acetic acid for $\mathrm{NO}_{2}$, silica gel imprignated with ammonium molybdate for $\mathrm{CO}$ and buffered potassium iodide for $\mathrm{O}_{3}$.

Air was bubbled with the air pump through an impinger containing the absorbing solution designed to react with each of the air pollutant studied. Each air pollutant was collected in this way and appropriate laboratory analysis of the resulting solutions was followed using colorimetric technique.

The technique involves using modified West-Graeke method for $\mathrm{SO}_{2}$, GriessSeltzman method for $\mathrm{NO}_{2}$, alkali method for $\mathrm{O}_{3}$ and reduction of the ammonium molybdate for CO.

\section{Results and Discussion}

$\mathrm{PM}_{2.5}$

Among common ambient air pollutants, particulate matter is currently under intensive epidemiological and toxicological investigation, especially $\mathrm{PM}_{2.5}$, as increasing evidence links it to various respiratory and cardiac effects and cardio pulmonary malfunctioning [17].

Results of Table 1 show that the mean levels of $\mathrm{PM}_{2.5}$ in the air around the vehicular traffic junctions within Nsukka metropolis, Enugu metropolis and Awgu semi-urban area were, $7.88 \pm 1.06,12.16 \pm 0.31$ and $1.67 \pm 0.11 \mu \mathrm{g} / \mathrm{m}^{3}$ respectively. The levels of $\mathrm{PM}_{2.5}$ in the three environments differed significantly. This was attributed to the varying levels of vehicular flow and traffic in the studied areas. The studied environments contained mean levels of $\mathrm{PM}_{2.5}$ in the air around the investigated traffic junctions in the following decreasing order; Enugu $>$ Nsukka $>$ Awgu as shown in Figure 1 . The mean hourly vehicular traffic 


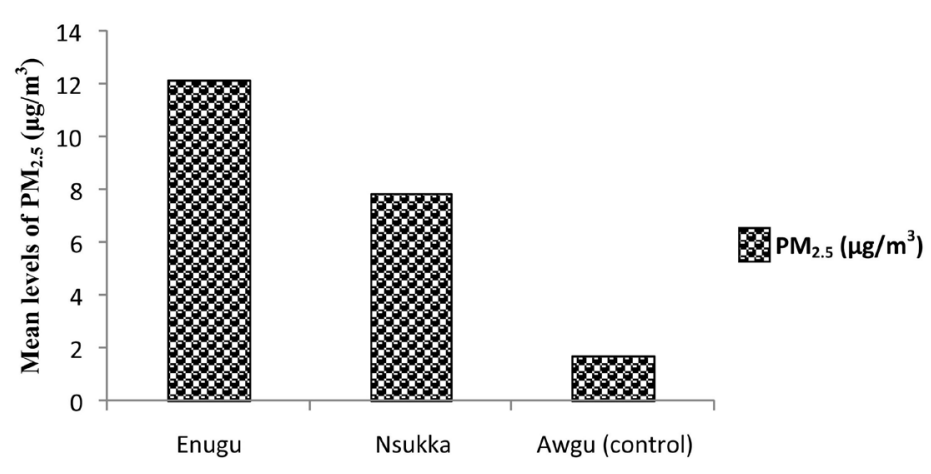

Figure 1. Bar chart representation of the mean levels of $\mathrm{PM}_{2.5}$ in the air around vehicular traffic junctions in Nsukka, Awgu, Enugu environments.

Table 1. Mean levels of outdoor-air pollutants in vehicular traffic junctions in Nsukka and Enugu Metropolis and Awgu semi-urban area.

\begin{tabular}{|c|c|c|c|c|c|c|}
\hline $\begin{array}{l}\text { City/ } \\
\text { Semi-urban }\end{array}$ & $\begin{array}{l}\text { Traffic } \\
\text { density }\end{array}$ & $\begin{array}{c}\mathrm{PM}_{2.5} \\
\left(\mu \mathrm{g} / \mathrm{m}^{3}\right)\end{array}$ & $\begin{array}{c}\mathrm{NO}_{2} \\
\left(\mu \mathrm{g} / \mathrm{m}^{3}\right)\end{array}$ & $\begin{array}{c}\mathrm{SO}_{2} \\
\left(\mu \mathrm{g} / \mathrm{m}^{3}\right)\end{array}$ & $\begin{array}{c}\mathrm{O}_{3} \\
\mu \mathrm{g} / \mathrm{m}^{3}\end{array}$ & $\begin{array}{c}\mathrm{CO} \\
(\mathrm{ppm})\end{array}$ \\
\hline Enugu & 2873 & $12.16 \pm 0.31$ & $23.83 \pm 2.40$ & $30.09 \pm 1.22$ & $66.54 \pm 2.67$ & $15.17 \pm 0.86$ \\
\hline Nsukka & 2015 & $7.88 \pm 1.06$ & $15.40 \pm 0.77$ & $21.92 \pm 0.84$ & $80.31 \pm 3.03$ & $10.31 \pm 0.65$ \\
\hline $\begin{array}{c}\text { Awgu } \\
\text { (control) }\end{array}$ & 587 & $1.67 \pm 0.11$ & $3.72 \pm 0.43$ & $2.96 \pm 0.22$ & $5.45 \pm 1.24$ & $1.18 \pm 0.09$ \\
\hline$F$ test $P$ value & & 0.01 & 0.01 & 0.01 & 0.00 & 0.01 \\
\hline $\begin{array}{c}{[16]} \\
\text { permissible } \\
\text { limits }\end{array}$ & 0 & 10 & 40 & 50 & 100 & 10 \\
\hline
\end{tabular}

Traffic density = number of vehicles per hour.

density within Enugu metropolis was 2873, while 2015 was for Nsukka metropolis and 587 was for Awgu semi-urban area thus giving credence to the varying $\mathrm{PM}_{2.5}$ levels in the studied environments.

The mean levels of $\mathrm{PM}_{2.5}$ in the investigated heavy-traffic junctions within Enugu metropolis was above the recommended permissible limits. Considering the health severity of exposure to this air pollutant, the health impact at consistent exposure to road users and the inhabitants living around the traffic junctions portends great danger.

[5] reported a higher mean value of $143.8 \pm 9.81 \mu \mathrm{g} / \mathrm{m}^{3}$ for $\mathrm{PM}_{2.5}$ in heavy traffic intersections in the commercial city of Jodhpur, India than what this study reported for $\mathrm{PM}_{2.5}$ in the investigated environments. $\mathrm{PM}_{2.5}$ can penetrate the lung barrier and enter the blood system.

Chronic exposure to particles contributes to the risk of developing cardiovascular and respiratory diseases, as well as lung cancer [17].

$\mathrm{NO}_{2}$

Results of Table 1 show that the mean levels of $\mathrm{NO}_{2}$ in the air around vehicu- 
lar traffic junctions in Nsukka metropolis, Enugu metropolis and Awgu semi-urban area were, $15.40 \pm 0.77,23.83 \pm 2.40$ and $3.72 \pm 0.43 \mu \mathrm{g} / \mathrm{m}^{3}$ respectively. The mean level of $\mathrm{NO}_{2}$ in the air around the traffic junctions within Enugu metropolis was found to be significantly higher than it was in vehicular traffic junctions within Nsukka metropolis and Awgu semi-urban area. The studied environments contained mean levels of $\mathrm{NO}_{2}$ in the air around the investigated vehicular traffic junctions in the following decreasing order; Enugu > Nsukka $>$ Awgu as shown in Figure 2.

The mean levels of $\mathrm{NO}_{2}$ in air around the vehicular traffic junctions in the studied environment were within the recommended permissible limits.

[9] reported a higher mean value of $35.9 \pm 0.51 \mu \mathrm{g} / \mathrm{m}^{3}$ for $\mathrm{NO}_{2}$ in major heavy traffic roads in the commercial city of Ibadan, Nigeria than what was obtained for $\mathrm{NO}_{2}$ in this study. According to [9], vehicular emission is one of the major sources of $\mathrm{SO}_{2}$ and $\mathrm{NO}_{2}$ contributing to air pollution in many cities in developing countries of the world.

Short term exposure to $\mathrm{NO}_{2}$ may cause air way responsiveness and lung injury while long term exposure have been associated with reduced immunity and respiratory diseases [1].

Equally, [18] reported that epidemiological studies have shown that symptoms of bronchitis in asthmatic children increase as a result of long term exposure to $\mathrm{NO}_{2}$. The levels of $\mathrm{NO}_{2}$ in the air around the vehicular traffic junctions in the studied environments were statistically significant.

$\mathrm{SO}_{2}$

Results of Table 1 show that the mean levels of $\mathrm{SO}_{2}$ in the air around the vehicular traffic junctions within Nsukka, metropolis, Enugu metropolis and Awgu semi-urban area were, $21.92 \pm 0.84,30.09 \pm 1.22$ and $2.06 \pm 0.22 \mu \mathrm{g} / \mathrm{m}^{3}$ respectively. The mean levels of $\mathrm{SO}_{2}$ in the air around the vehicular traffic junctions within Enugu metropolis were statistically higher than it was in the air around vehicular traffic junctions within Nsukka metropolis and Awgu semi-urban area respectively. The studied environments contained mean levels of $\mathrm{SO}_{2}$ in the air around the investigated vehicular traffic junctions in the following decreasing order; Enugu $>$ Nsukka $>$ Awgu as shown in Figure 3.

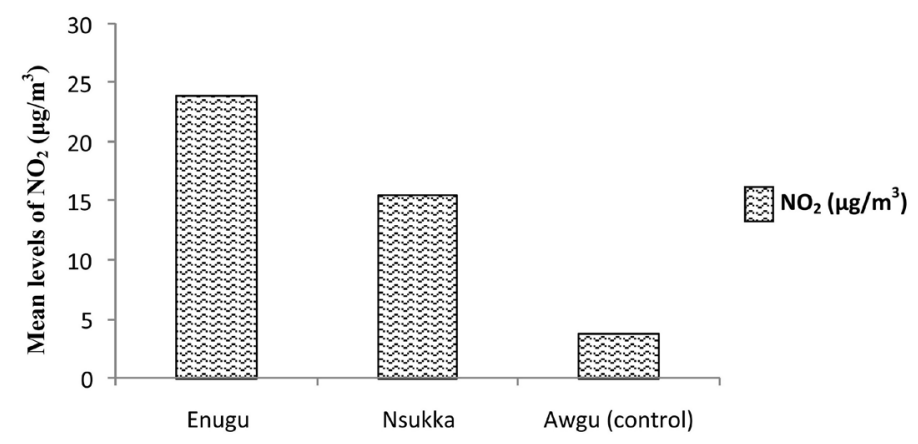

Figure 2. Bar chart representation of the mean levels of $\mathrm{NO}_{2}$ in air around the vehicular traffic junctions in Nsukka, Awgu and Enugu environments. 


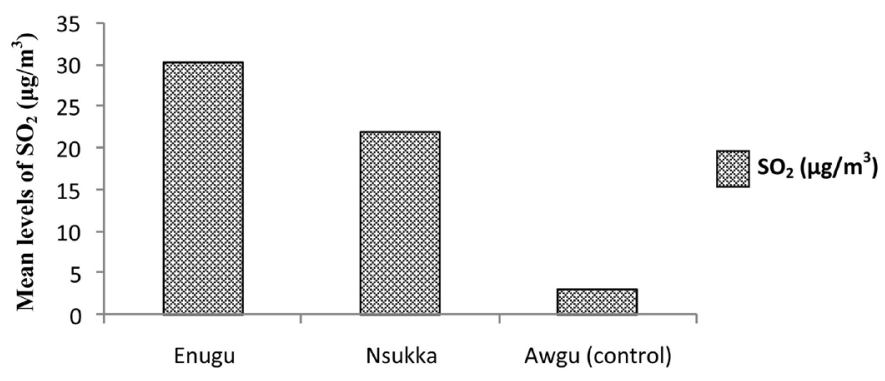

Figure 3. Bar chart representation of the mean levels of $\mathrm{SO}_{2}$ in air around vehicular traffic junctions in Nsukka, Awgu and Enugu environments.

As stated earlier, the differences in traffic density in addition to the use of vehicles at varying physical and mechanical conditions and fuel usage of varying quality could have significantly contributed to the varying mean levels of $\mathrm{SO}_{2}$ in the air around traffic junctions in the three studied environment.

The mean levels of $\mathrm{SO}_{2}$ in the air around the vehicular traffic junctions in the three studied environments were within permissible limits.

[5] reported a lower mean value of $16.4 \pm 1.50 \mu \mathrm{g} / \mathrm{m}^{3}$ for $\mathrm{SO}_{2}$ in the air around traffic inter sections in the commercial city of Jodhpur, India than what this study obtained for $\mathrm{SO}_{2}$ in the investigated environments. According to [1], consistent exposure to high levels of $\mathrm{SO}_{2}$ causes inflammation of the respiratory tract which ultimately leads to prolonged coughing, mucus secretion, aggravation of asthma and chronic bronchitis.

$\mathrm{O}_{3}$

Results of Table 1 show that the mean levels of $\mathrm{O}_{3}$ in the air around the vehicular traffic junctions in Nsukka, Awgu and Enugu environments were, $80.31 \pm$ $3.03,5.45 \pm 1.24$ and $66.34 \pm 2.67 \mu \mathrm{g} / \mathrm{m}^{3}$ respectively. The mean levels of $\mathrm{O}_{3}$ in the air around vehicular traffic junctions in Nsukka environment were significantly higher than it was in Enugu metropolis, and Awgu semi-urban area respectively.

The mean levels of $\mathrm{O}_{3}$ in the air around the vehicular traffic junction in the three studied environments were within the WHO recommended permissible limits of the pollutant in the air. The studied environments contained mean levels of $\mathrm{O}_{3}$ in the air around the investigated vehicular traffic junctions in the following decreasing order; Nsukka $>$ Enugu $>$ Awgu as shown in Figure 4.

The levels of $\mathrm{O}_{3}$ in the air around vehicular traffic junctions in Awgu was significantly lower compared to the levels of the air pollutant in the other studied environments probably because of decreased vehicular flow (traffic density) which gave to rise to fewer air pollutant emission.

[5] reported a mean value of $82.9 \mu \mathrm{g} / \mathrm{m}^{3}$ for $\mathrm{O}_{3}$ in traffic inter sections in the commercial city of Jodhpur, India which compared very well with what was obtained in this study for $\mathrm{O}_{3}$ in the air around vehicular traffic junctions in Nsukka metropolis. Excessive ozone in the air can have a marked effect on human health.

[1] reported that excessive exposure to $\mathrm{O}_{3}$ by people causes breathing prob- 
lems, triggers asthma, reduces lung function which ultimately leads to lung diseases and equally damage to the brain.

$\mathrm{CO}$

In traffic related exposure studies and epidemiological investigations, another important pollutant is carbon monoxide (CO), which results from the incomplete combustion of natural gas, diesel or gasoline in traffic engines.

According to [19], high concentrations of CO generally occur in areas with heavy traffic intensity and congestion.

Results of Table 1 show that the mean levels of $\mathrm{CO}$ in the air around vehicular traffic junctions in Enugu, Nsukka and Awgu environments were, $15.17 \pm 0.86$, $11.31 \pm 0.65$ and $1.18 \pm 0.09 \mathrm{ppm}$ respectively.

The mean levels of $\mathrm{CO}$ in the air around traffic junction in Enugu and Nsukka metropolitan environments were above that WHO recommended permissible limits of the air pollutant in the air. The studied environments contained mean levels of $\mathrm{CO}$ in the air around the investigated vehicular traffic junctions in the following decreasing order; Enugu $>$ Nsukka $>$ Awgu as shown in Figure 5.

The levels of $\mathrm{CO}$ in the air around vehicular traffic junctions in the three studied environments differed significantly.

The mean values obtained in this study for $\mathrm{CO}$ in the air around traffic junctions in Enugu and Nsukka metropolitan environments was in agreement with $12.00 \mathrm{pm}$ and $10.00 \mathrm{pm}$ reported by [20] for $\mathrm{CO}$ in vehicular intersections in the cities of Kosole and Ikorodu respectively in Lagos State.

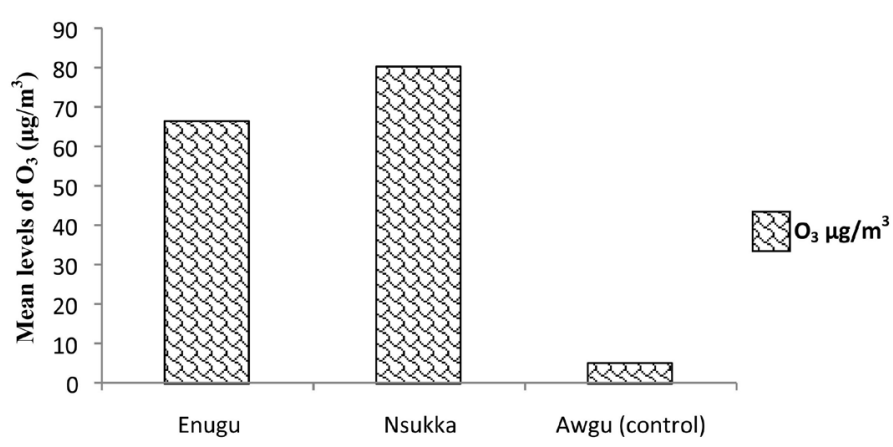

Figure 4. Bar chart representation of mean levels of $\mathrm{O}_{3}$ in the air around vehicular traffic junctions in Nsukka, Awgu and Enugu environments.

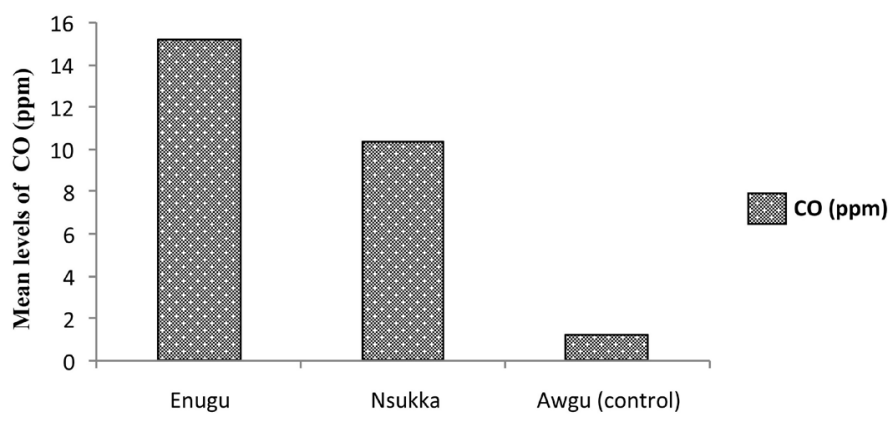

Figure 5. Bar chart representation of the mean levels of $\mathrm{CO}$ in the air around vehicular traffic junctions in Enugu, Nsukka and Awgu environments. 
After inhalation by the lungs, $\mathrm{CO}$ is absorbed by the blood and inhibits oxygen transport by competing with oxygen for combination with haemoglobin and thus leads to hypoxia.

Like many other air pollutants, CO levels in urban regions are highly influenced by such factors as traffic density, traffic congestion and meteorological conditions [1].

\section{Conclusions}

The study observed that traffic density was the most important factor influencing the levels of the investigated air pollutants in the air around vehicular traffic junctions in Nsukka, Enugu and Awgu environments. The investigated air pollutants were statistically significant in the air around the vehicular traffic junctions in the studied environments. The mean levels of $\mathrm{PM}_{2.5}, \mathrm{NO}_{2}, \mathrm{SO}_{2}, \mathrm{O}_{3}$ and $\mathrm{CO}$ were very significantly higher in the air around vehicular traffic junctions in Enugu and Nsukka metropolitan environments than in Awgu environment. Further buttressing literature reports that areas with high traffic density and traffic congestion usually witness high level of air pollution arising from vehicular emissions compared to a rural or semi-urban environment with low traffic density and congestion.

The mean levels of $\mathrm{PM}_{2.5}$ and $\mathrm{CO}$ in the air around vehicular traffic junctions within Enugu metropolis as well as $\mathrm{CO}$ in the air around vehicular traffic junctions within Nsukka metropolis were above the recommended permissible limits of air quality. Apart from high traffic density, other factors that could have accounted for the high levels of the determined air pollutants in the air around traffic junctions in Nsukka and Enugu metropolis were the usage of poor quality fuel, preponderance of poorly maintained vehicles on the road and non-adherence to traffic light commands by motorists. It is very important that the government of Nigeria at all levels should look critically into the physical and mechanical states of vehicles plying on the roads in major Nigerian cities, quality of fuel dispensed to motorists and impose strict penalties on those who drive old, rickety and poorly maintained vehicles and those that subvert traffic rules, in order to drastically stem the levels of emission of toxic air pollutants on the environment through vehicular activities.

\section{Acknowledgements}

The researchers of this study profoundly express their gratitude to the managements of Scientific Equipment Development Institute, Enugu and Nnamdi Azikiwe University, Awka for allowing us an unfettered access into their chemical laboratories for the analysis of our samples. To all those that helped us to obtain the traffic densities of the studied areas especially our research students, we are highly grateful.

\section{Conflicts of Interest}

The authors declare no conflicts of interest regarding the publication of this paper. 


\section{References}

[1] Han, X.L. and Naeher, L.P. (2015) A Review of Traffic-Related Air Pollution Exposure Assessment Studies in the Developing World. Environment International, 32, 106-120. https://doi.org/10.1016/j.envint.2005.05.020

[2] Kulkarni, M.M. and Patil, R.S. (1999) Monitoring of Daily Integrated Exposure of Outdoor Workers to Respirable Particulate Matter in an Urban Region of India. Environmental Monitoring Assessment, 56, 129-146.

[3] Chan, L.U., Kwok, W.S. and Chan, C.Y. (2000) Human Exposure to Respirable Suspended Particulate and Airborne Lead in Different Roadside Microenvironments. Chemosphere, 41, 93-99.

[4] Bhatia, S.C. (2019) Environmental Pollution and Control in Chemical Process Industries. Khanna Publishers, Delhi, 163-167.

[5] Rumana H.S., Sharma R.C., Beniwal V. and Sharma A.K. (2014) A Retrospective Approach to Asses Human Health Risks Associated with Growing Air Pollution in Urbanized Area of Thar Desert, Western Rajasthan, India. Journal of Environmental Health Science and Engineering, 12, 23-32. https://doi.org/10.1186/2052-336X-12-23

[6] Zangury, E., Moullee, Y.L. and Momes, I. (2000) Exposure of Paris Taxi Drivers to Antomobile Air Pollutants within Their Vehicles. Occupational and Environmental Medicine, 57, 406-410.

[7] Komolafe, A.A., Adegboyega, S.A., Anifowose, A.Y., Akinluyi, F.O. and Awoniran, D.R. (2014) Air Pollution and Climate Change in Lagos, Nigeria: Needs for Proactive Approaches to Risk Management and Adaptation. American Journal of Environmental Science, 10, 412-423. https://doi.org/10.3844/ajessp.2014.412.423

[8] Ojo, O.S. and Awokola, O.S. (2012) Investigation of Air Pollutant from Automobiles and Inter Sections on Some Selected Major Roads in Ogbomoso, South Western, Nigeria. IOSR Journal of the Chemical and Civil Engineering, 1, 31-35. https://doi.org/10.9790/1684-0143135

[9] Ipeaiyeda, A.R. and Adegboyega, S.A. (2007) Assessment of Air Pollutant Concentrations near Major Roads in Residential, Commercial and Industrial Areas in Ibadan City, Nigeria. Journal of Health and Pollution, 7, 11-21. https://doi.org/10.5696/2156-9614-7-13.11

[10] Lntengs, F.K. and Edward, J.T. (2010) The Atmosphere: An Introduction to Meteorology. 8th Edition, Prentice Hall, Upper Saddle River, 510-513.

[11] World Health Organization (2004) WHO Methods Data Sources for Global Causes of Death 2000-2012. Global Health Estimates Technical Paper WHO/HIS/HSI/ GHE/2014.7.

[12] Wjst, M., Reltmier, P., Dold, S., Wulff, A. and Matius, E. (1993) Road Traffic and Exercise Effect on Respiratory Health in Children. BMJ Clinical Research, 307, 596-600.

[13] International Agency for Research on Cancer (2014) IARC Monographs on the Evaluation of Carcinogenic Risks to Humans.

[14] Environmental Protection Agency (2017) Health and Environmental Effects of Hazardous Air Pollutants.

http://www.epa.gov/climatechange/emissions/usinrentoryreport.html

[15] American Standard for Testing of Materials (2001) Atmospheric Analysis. Occupation Health, 11, 251-256.

[16] World Health Organization (2010). Guidelines for Air Quality, Geneva, Switzerland. 
[17] Magari, S.R., Schwartz, J., Williams, P.L., Hausar, R., Smith, T.J. and Christian, D.C. (2002) The Association between Personal Measurements of Environmental Exposure to Particulates Heart Rate Variability. Epidemiology, 13, 305-310.

[18] Farrar, O., Dingle, P. and Tan, R. (2001) Exposure to Nitrogen Dioxide in Buses, Taxes and Bicycles in Perth, Western Australia. Bulletin of Environmental Contamination Toxicology, 66, 433-438.

[19] Gomez-Perales, J.E., Colvile, R.N., Nieunenhuijsen, M.J., Guitierrez Avedoy, V.J., et al. (2004) Commuters Exposure to $\mathrm{PM}_{2.5}, \mathrm{CO}$ and Benzene in Public Transport in the Metropolitan Area of Mexico City. Atmospheric Environment, 38, 1219-1229.

[20] Njoku, K.L., Rumide, T.J., Akinola, M.O., Adesuyi, A.A. and Anuoluwapo, O. (2016) Ambient Air Quality Monitoring in Metropolitan City of Lagos, Nigeria. Journal of Applied Science and Environmental Management, 20, 178-185.

https://doi.org/10.4314/jasem.v20i1.21 